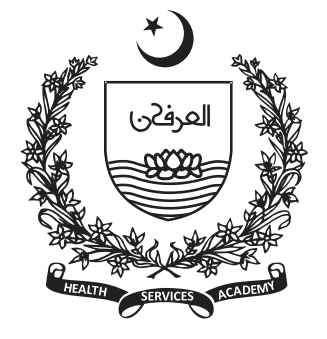

1Bacha Khan Dental College, Mardan, Pakistan.

2Peshawar Dental College,

Peshawar, Pakistan.

Corresponding Author:

Mussarat Hussain

Email:

shania1234543@gmail.com

\title{
Frequency of gingivitis in pregnancy in patients reporting to Bacha Khan Dental College, Mardan
}

\author{
Mussarat Hussain ${ }^{1}$, Muhammad Naeem ${ }^{1}$, Imran Khattak², Raham Zaman ${ }^{1}$, \\ Sajila Raziq ${ }^{1}$
}

\section{Abstract}

Background: The objective of this study was to determine the frequency of gingivitis in pregnant females reporting to Bach Khan Dental College, Mardan.

Methods: This cross-sectional descriptive study was conducted on 70 pregnant women by using non-probability consecutive sampling technique. Pregnant females with age range of 20 to 45 years, having adequate oral hygiene, no systemic disease affecting gingival health and Pakistani nationals were included in the study. Age, trimester of pregnancy, employment, brushing habit and presence of gingivitis were recorded. Loe and Silness gingival index was used to record the various grades of gingivitis (normal gingiva, mild, moderate, and severe gingivitis). Descriptive statistics were computed. Comparison was done for the presence of gingivitis by age, employment, brushing habits, and trimester using Chi-Square test. $\mathrm{P} \leq 0.05$ was considered significant.

Results: The mean age of the study was 28.44 years (SD, 5.65 years). The gingivitis was present in $40(57.1 \%)$ participants. Of total $22(31.4 \%)$ were government employees. Most common pattern of brushing teeth was 'twice a day' $(n=28,40 \%)$ and most common trimester of pregnancy was third $(n=28$, $40 \%$ ). Most of the pregnant female belonged to age group 26 to 30 years $(n=28,40 \%)$ and 20 to 25 years $(n=21,30 \%)$. Most common form of gingivitis was severe $(n=25,35.71 \%)$ followed by moderate $(n=13,18.57 \%)$. In pregnant females the effect of brushing pattern, employment, trimesters and age on gingivitis was not statistically significant $(P>0.05)$.

Conclusion: The frequency of gingivitis in pregnancy is quite high in our study. The dental practitioners should be vigilant and advise the plaque control and prompt treatment of gingivitis to pregnant females to prevent progression to periodontitis.

Keywords: Pregnancy; gingivitis; pregnant women; pregnancy associated gingivitis; gingival index

\section{Introduction}

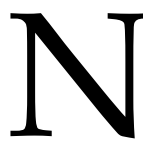

of periodontium covers the alveolar process and surrounds the cervical area of the tooth.(1) The healthy gingiva in general have coral pink colour and is dependent on the vascular supply, thickness of tissue, amount of keratinized 
epithelium, and melanin pigments.(2) Gingivitis is reversible inflammation of tooth supporting tissue caused by plaque in oral cavity. There is no loss of attachment apparatus in the gingivitis.(3)

Due to hormonal changes in pregnancy, the risk of gingivitis increases.(4-6) In pregnant women, the rise in progesterone level is 10 times more than in women without pregnancy,(7) a circumstance that promotes the specific pathogenic microbial growth involved in gingivitis. During pregnancy there are changes in immune system leading to alteration in host reaction to bacterial plaque and aggravating gingivitis.(2) It is established that gingivitis in pregnant women is dependent on, but not related to, the amount of plaque present. And it is also documented proper oral hygiene in pregnant females can partly counteract hormonal effect.(3)

According to earlier studies the gingivitis prevalence ranges from $30 \%$ to $100 \%$ during pregnancy.(8) While some cross-sectional studies reported that the frequency of gingivitis in pregnancy was $86.2 \%$ in Thailand population, $89 \%$ in Ghana, and $47 \%$ in Brazilian population.(9-11) Another cross sectional study conducted in Nigeria reported that the prevalence of gingivitis in pregnant women was $85.2 \%$.

To our knowledge no research has been conducted in Mardan population on frequency of gingivitis in pregnant women. There is a large variation in prevalence of pregnancy associated gingivitis in previous studies depending on population. Our results can be different from other studies due to ethnic, genetic and environmental factors. This study will aid the clinicians to give due attention to manage the pregnancy associated gingivitis and intercept its progression to irreversible condition called periodontitis.

The objective of this study was to determine the frequency of gingivitis in pregnant females reporting to Bach Khan Dental College, Mardan.

\section{Methodology}

This cross-sectional descriptive study was conducted on 70 pregnant women presenting to
Bacha Khan Dental College, Mardan by using non-probability consecutive sampling technique from January 2019 to October 2019. Hospital ethical approval was obtained prior to conducting this research. After explaining in detail about the aim of study to each participant and a written consent was taken.

Pregnant females with age range of 20 to 45 years, having adequate oral hygiene (no major plaque and calculus deposits), no systemic disease affecting gingival health and Pakistani national were included in the study. A prestructured pro forma was used to collect data from participants like age, trimester of pregnancy, employment (yes or no), brushing habit and gingival status. After detailed history, an examination was carried out under artificial light source using mouth mirror and periodontal explorer. Gingival status was checked by a periodontal specialist having two-year experience in Periodontology. The presence or absence of gingivitis was recorded. Gingivitis was diagnosed on clinical basis by bleeding on probing, swelling and change in color of gingiva. Loe and Silness gingival index (GI) was used to record the various grade of gingivitis as follows; grade $0=$ normal gingiva; grade $1=$ mild inflammation (slight change in colour and mild edema but no bleeding on probing) ; grade $2=$ moderate inflammation (erythema, edema and bleeding on probing); grade $3=$ severe inflammation (marked redness and edema, ulceration with spontaneous bleeding).(12) The scores of GI from each of the four surfaces (distal, mesial, facial and lingual) of the tooth were averaged. Then mean score for each participant was obtained by dividing number of teeth examined on total GI score.

Data analysis was done in SPSS 20. The calculation of frequencies and percentages was done for qualitative variables like presence of gingivitis, grade of gingivitis and trimester of pregnancy. Mean and standard deviation was computed for continuous variables like age. Comparison was done for the presence of gingivitis by age, employment, brushing habits, and trimester using Chi-Square test. $\mathrm{P} \leq 0.05$ was considered significant. 


\section{Results}

The mean age of 70 pregnant females was 28.44 years (SD, 5.65 years) with range from 20 to 40 years. The gingivitis was present in $40(57.1 \%)$ participants. Of total sample $22(31.4 \%)$ were doing some sort of government employment and rest were house wives. Most common pattern of brushing teeth among these pregnant women was 'twice a day' $(n=28,40 \%)$ followed by 'once a day' $(\mathrm{n}=27,38.6 \%)$ and 'less frequent' $(\mathrm{n}=15,21.4 \%)$. The most common trimester of pregnancy was third $(\mathrm{n}=28,40 \%)$ followed second $(n=25,35.7 \%)$ and least was first $(n=17,24.3 \%)$. Most of the pregnant female belonged to age group 26 to 30 years $(n=28,40 \%)$ and 20 to 25 years $(n=21,30 \%)$. The details are shown in Table 1. Most common form of gingivitis was severe $(n=25,35.71 \%)$ followed by moderate $(n=13,18.57 \%)$ and least was mild gingivitis $(\mathrm{n}=2,2.86 \%)$. (Fig 1)

In pregnant females the effect of brushing pattern, employment, trimesters and age on gingivitis was not statistically significant $(\mathrm{P}>0.05)$. The detailed statistics are shown in Table 2.

Table 1: Frequency of gingivitis, employment, rushing habit, trimester and age groups

\begin{tabular}{|c|c|c|c|}
\hline & & Frequency & Percent \\
\hline \multirow{3}{*}{ Gingivitis } & Present & 40 & 57.1 \\
\hline & Absent & 30 & 42.9 \\
\hline & Total & 70 & 100.0 \\
\hline \multirow{3}{*}{$\begin{array}{c}\text { Employm } \\
\text { ent }\end{array}$} & Yes & 22 & 31.4 \\
\hline & No & 48 & 68.6 \\
\hline & Total & 70 & 100.0 \\
\hline \multirow{4}{*}{$\begin{array}{c}\text { Brushing } \\
\text { habit }\end{array}$} & $\begin{array}{l}\text { Less } \\
\text { frequent }\end{array}$ & 15 & 21.4 \\
\hline & $\begin{array}{l}\text { Once a } \\
\text { day }\end{array}$ & 27 & 38.6 \\
\hline & $\begin{array}{l}\text { Twice a } \\
\text { day }\end{array}$ & 28 & 40.0 \\
\hline & Total & 70 & 100.0 \\
\hline \multirow{4}{*}{ Trimester } & $1^{\text {st }}$ & 17 & 24.3 \\
\hline & $2^{\text {nd }}$ & 25 & 35.7 \\
\hline & $3^{\text {rd }}$ & 28 & 40.0 \\
\hline & Total & 70 & 100.0 \\
\hline
\end{tabular}

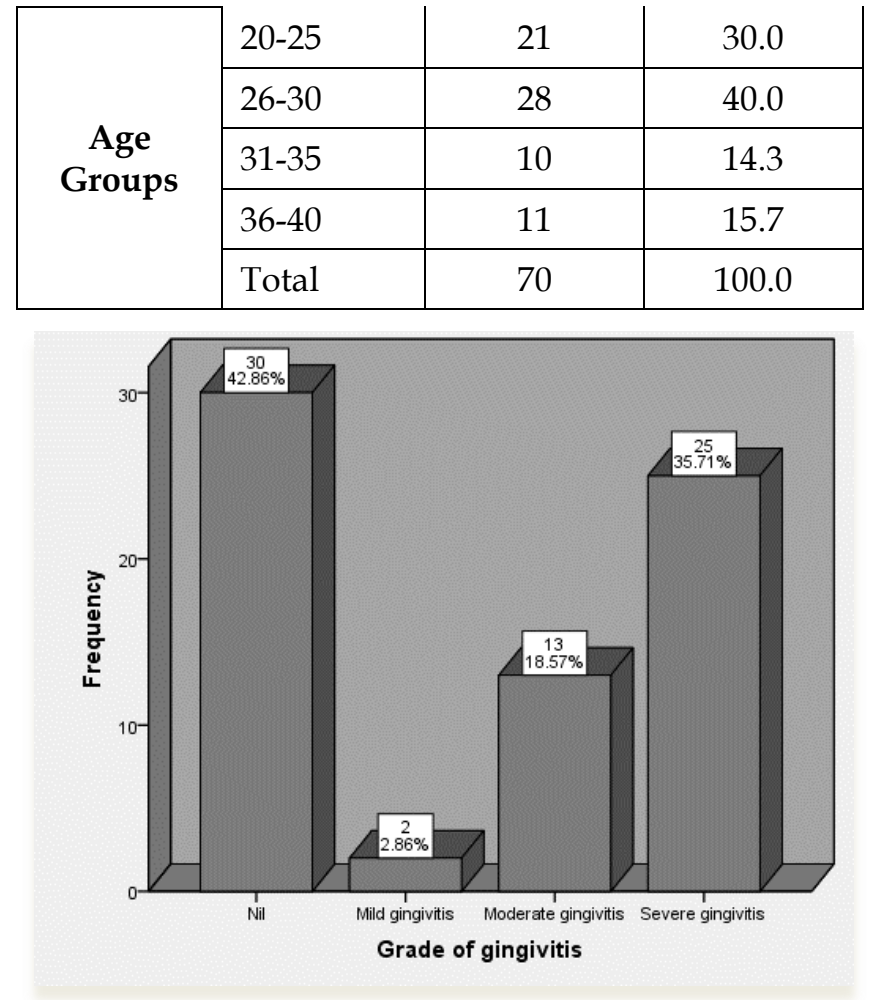

Fig 1: Frequency of various grades of gingivitis

Table 2: Comparison of gingivitis among brushing habits, employment, trimester and age groups

\begin{tabular}{|c|c|c|c|c|c|c|}
\hline & \multicolumn{3}{|c|}{ Gingivitis } & \multirow{3}{*}{$\begin{array}{c}\begin{array}{c}\text { P- } \\
\text { value* }^{*}\end{array} \\
\%\end{array}$} & \\
\hline & & \multicolumn{2}{|c|}{ Present } & \multirow{2}{*}{$\frac{\text { Absent }}{n}$} & & \\
\hline & & $\mathbf{n}$ & $\%$ & & & \\
\hline \multirow{3}{*}{$\begin{array}{l}\text { Brushing } \\
\text { habit }\end{array}$} & \begin{tabular}{|l|} 
Less \\
frequent
\end{tabular} & 8 & 53.3 & 7 & 46.7 & \multirow{3}{*}{.877} \\
\hline & \begin{tabular}{|l|} 
Once a \\
day
\end{tabular} & 15 & 55.6 & 12 & 44.4 & \\
\hline & $\begin{array}{l}\text { Twice a } \\
\text { day }\end{array}$ & 17 & 60.7 & 11 & 39.3 & \\
\hline \multirow{2}{*}{$\begin{array}{l}\text { Employ } \\
\text { ment }\end{array}$} & Yes & 11 & 50.0 & 11 & 50.0 & \multirow{2}{*}{.414} \\
\hline & No & 29 & 60.4 & 19 & 39.6 & \\
\hline \multirow{3}{*}{$\begin{array}{l}\text { Trimeste } \\
\mathbf{r}\end{array}$} & $1^{\text {st }}$ & 6 & 35.3 & 11 & 64.7 & \multirow{3}{*}{.097} \\
\hline & $3^{\text {rd }}$ & 17 & 60.7 & 11 & 39.3 & \\
\hline & $2^{\text {nd }}$ & 17 & 68.0 & 8 & 32.0 & \\
\hline \multirow{4}{*}{$\begin{array}{l}\text { Age } \\
\text { Groups } \\
\text { (years) }\end{array}$} & $20-25$ & 14 & 66.7 & 7 & 33.3 & \multirow{4}{*}{.069} \\
\hline & $26-30$ & 14 & 50.0 & 14 & 50.0 & \\
\hline & $31-35$ & 3 & 30.0 & 7 & 70.0 & \\
\hline & $36-40$ & 9 & 81.8 & 2 & 18.2 & \\
\hline
\end{tabular}

${ }^{*}$ Chi-square test; $\mathrm{P}<0.05$ was significant level 


\section{Discussion}

This study was carried out to know the frequency of gingivitis in pregnant females. Our results showed that there was $57.1 \%$ gingivitis in pregnant females. The effect of brushing pattern, employment, trimesters and age on pregnancy associated gingivitis was not statistically significant $(\mathrm{P}>0.05)$.

For this study we selected participants with satisfactory oral hygiene having no obvious plaque and calculus deposits. The presence bad oral hygiene can itself be an etiologic factor for gingivitis so we excluded the cases with poor oral hygiene.(13) This was done to control confounder in this study.

In our study the frequency of gingivitis was $57.1 \%$ in pregnant women. Previous studies reported variable rate of gingivitis in pregnancy. Published literature have shown that the prevalence rates of gingivitis during pregnancy range between $30 \%$ and $100 \% \cdot(14,15)$ The prevalence of gingivitis in pregnancy was reported $85.2 \%$ in Nigerian population ${ }^{(16)}$ and $86.2 \%$ in Thailand population (11). The variability in findings can be attributed to genetic, hormonal and oral hygiene habit variation. In our study we selected pregnant females with adequate oral hygiene and most of our participants brushed their teeth more than two times per day. Due to these reasons the frequency of gingivitis may be less in our study. Another study conducted in Nepal reported that the frequency of gingivitis was $40 \%$ in pregnancy. The oral hygiene was good in their study and most of participants brushed their after every meal. (17) These results are near to our findings. Another study conducted on Pregnant women in India reported that gingivitis was more prevalent among pregnant than non-pregnant women. they reported $71.9 \%$ gingivitis in pregnant women.(18)

Our findings showed that most common pattern of brushing teeth among these pregnant women was twice a day followed by once a day and less frequent. The fact the all the participants were brushing their teeth may be due the fact that we included in our study only pregnant females with adequate oral hygiene. Al-Rayyan et al.(16) researched on large sample of pregnant females $(n=580)$ in Jordon population and reported that most common pattern of brushing was less effective. The variation can be attributed to sample size difference and awareness among participants. Another study conducted in Karachi showed that most common (65.6\%) pattern of brushing was once a day among pregnant women.(19)
Our results showed that most common form of gingivitis was severe followed by moderate and least was mild gingivitis. A study conducted in Nigeria on prevalence of gingivitis in pregnant women showed that most common pattern of gingivitis was mild and least was severe gingivitis.(2) The difference in results can be due to genetic and hormonal difference of our population from Nigerian population.

Current study found that there was no significant effect of brushing pattern, employment, trimesters and age on gingivitis in pregnancy. Similar results were found by Al-Rayyan et al.(16)

\section{Conclusion}

The frequency of gingivitis in pregnancy is quite high in our study. The dental practitioners should be vigilant and advise the plaque control and prompt treatment of gingivitis to pregnant females to prevent progression to periodontitis.

\section{References}

1. Newman MG, Takei H, Klokkevold PR, Carranza FA. Newman and Carranza's Clinical Periodontology E-Book: Elsevier Health Sciences; 2018.

2. Soroye MO, Ayanbadejo PO. Prevalence of gingivitis and perception of gingival colour among pregnant women attending the antenatal clinic of Lagos University Teaching Hospital, Idi-Araba. J Orofac Sci 2016;8(1):53.

3. $\mathrm{Wu} \mathrm{M}$, Chen S-W, Jiang S-Y. Relationship between gingival inflammation and pregnancy. Mediators of inflamm 2015;2015(1):1-7.

4. González-Jaranay M, Téllez L, Roa-López A, Gómez-Moreno G, Moreu G. Periodontal status during pregnancy and postpartum. PloS One 2017;12(5):e0178234.

5. Carrillo-de-Albornoz A, Figuero E, Herrera D, Cuesta P, Bascones-Martínez A. Gingival changes during pregnancy: III. Impact of clinical, microbiological, immunological and socio-demographic factors on gingival inflammation. J Clin Periodontol 2012;39(3):27283.

6. Silva de Araujo Figueiredo C, Gonçalves Carvalho Rosalem C, Costa Cantanhede AL, Abreu Fonseca Thomaz ÉB, Fontoura Nogueira da Cruz MC. Systemic alterations and their oral manifestations in pregnant women. J Obstetric Gynaecol Res 2017;43(1):16-22. 
7. Gürsoy M, Pajukanta R, Sorsa T, Könönen E. Clinical changes in periodontium during pregnancy and post-partum. J Clin Periodontol 2008;35(7):576-83.

8. Mealey BL, Moritz AJ. Hormonal influences: effects of diabetes mellitus and endogenous female sex steroid hormones on the periodontium. Periodontol 2003;32(1):59-81.

9. Nuamah I, Annan B. Periodontal status and oral hygiene practices of pregnant and non-pregnant women. East Afri Med J 1998;75(12):712-4.

10. Vogt M, Sallum AW, Cecatti JG, Morais SS. Factors associated with the prevalence of periodontal disease in low-risk pregnant women. Reproductive Health 2012;9(1):3.

11. Rakchanok N, Amporn D, Yoshida Y, HarunOr-Rashid M, Sakamoto J. Dental caries and gingivitis among pregnant and non-pregnant women in Chiang Mai, Thailand. Nagoya J Med Sci 2010;72(1-2):43-50.

12. Löe H, Silness J. Periodontal disease in pregnancy I. Prevalence and severity. Acta Odontol Scand 1963;21(6):533-51.

13. Sreenivasan PK, Prasad KV. Distribution of dental plaque and gingivitis within the dental arches. J Int Med Res 2017;45(5):1585-96.
14. Yalcin F, Eskinazi E, Soydinc M, Basegmez C, Issever $\mathrm{H}$, Isik $\mathrm{G}$, et al. The effect of sociocultural status on periodontal conditions in pregnancy. J Periodontol 2002;73(2):178-82.

15. Moss KL, Beck JD, Offenbacher S. Clinical risk factors associated with incidence and progression of periodontal conditions in pregnant women. J Clin Periodontol 2005;32(5):492-8.

16. Al-Rayyan E, Masarwa N, Barakat M. Frequency of gingivitis in pregnancy: A comparative study between first and third trimesters of pregnancy. J Royal Med Servic 2013;102(442):1-6.

17. Erchick D, Rai B, Agrawal N, Khatry S, Katz J, LeClerq $S$, et al. Oral hygiene, prevalence of gingivitis, and associated risk factors among pregnant women in Sarlahi District, Nepal. Biomed Cent Oral Health 2019;19(1):2.

18. Patil S, Ranka R, Chaudhary M, Hande A, Sharma P. Prevalence of dental caries and gingivitis among pregnant and nonpregnant women. J Datta Megh Med Sci Univ 2018;13(1):44.

19. Saima S, Masooma Z, Aamna Qazi, Syed Muneeb Y. Oral hygiene among pregnant women; practices and knowledge. Professional Med J 2015;22(1): 106-111. 